Artigos

Volume 8 - 2018 | n. 6

\title{
Combates pela Educação: as propostas de financiamento da educação no 'Manifesto dos Pioneiros da Educação Nova'
}

\author{
Daniel Santos Braga \\ Universidade Federal de Minas Gerais (UFMG), Belo Horizonte/MG - Brasil
}

\section{Resumo}

O artigo objetiva identificar as propostas de organização do financiamento da educação no Brasil no documento denominado Manifesto dos Pioneiros da Educação Nova de 1932 e analisar tais propostas em relação ao contexto político e social do período em foi redigido. $O$ texto histórico, pensado como um documento/monumento, revela que os rumos da educação e da sociedade brasileira estavam em disputa, e que a intenção dos autores era exatamente apresentar um projeto societário. Concluiu-se que, ainda que o manifesto não tenha suscitado as transformações pretendidas no momento da redação, inspirou os modelos de organização do financiamento público da educação brasileira contemporânea.

Palavras-chave: Manifesto dos Pioneiros. Financiamento da Educação. História da Educação.

\section{Fights for Education: proposals for education funding in the 'Pioneers of New Education Manifesto'}

\begin{abstract}
The article aims to identify the proposals of organization of education funding in Brazil in the 1932 document entitled Pioneers of New Education Manifesto and to analyze such proposals in relation to the political and social context of the period in which it was written. The historical text, thought as a document/monument, reveals that the directions of Brazilian education and society were in dispute, and that the intention of the authors was precisely to present a societal project. It was concluded that, although the manifesto did not elicit the desired transformations at the time of writing, it inspired the models of organization of the public funding of contemporary Brazilian education.
\end{abstract}

Keywords: Pioneers Manifesto. Education Funding. History of Education. 
Combates pela Educação

\section{Introdução}

Recentemente, aprofunda-se no Brasil o debate sobre o financiamento da educação, tanto na academia quanto no movimento organizado dos professores. Nas universidades, esse debate se percebe com o aumento da produção científica e a organização de grupos de pesquisa locais, regionais e nacionais sobre o tema. As associações e sindicatos de professores, por sua vez, passam a elencar, cada vez mais, em suas pautas de luta, o aumento dos investimentos em Educação. Por fim, percebe-se também a relevância dessa discussão a partir da ampliação, nas três últimas décadas, de formulações por parte dos governos, de políticas públicas relacionadas ao financiamento.

Porém, o financiamento não é assunto recente nos debates sobre Educação no Brasil, podendo ser encontrado em diversos momentos da história. Um desses momentos em que ela se apresenta com mais profundidade (e tensionalidade) se dá no contexto da elaboração e publicação de um manifesto, fundamental para o pensamento pedagógico e educacional brasileiro: o 'Manifesto dos Pioneiros da Educação Nova', em 1932. Escrito sob liderança e auspícios de Fernando de Azevedo e contando com a colaboração de Anísio Teixeira, Lourenço Filho entre outras emblemáticas personalidades do cenário político nacional, o texto está inserido em um contexto histórico marcado pelos contrastes e contradições entre os diferentes projetos de país postos. O texto faz uma avaliação da conjuntura educacional do Brasil, apontando, segundo seus autores, seus principais problemas, assim como possibilidades de soluções. O documento se mostra também como um libelo contra determinados setores da sociedade, principalmente aqueles que defendiam a organização escolar nacional - assim como o seu financiamento -, privilegiando os grupos particulares em detrimento das escolas públicas.

Nesse sentido, um dos elementos presentes no manifesto de 1932 é a questão das disputas em torno do financiamento público da Educação. Como o Estado brasileiro poderia suprir as suas crônicas carências de recursos educacionais que emperravam o progresso nacional? De que forma se daria a organização do financiamento da construção de escolas, assim como da formação e do pagamento de professores? De onde seriam captados esses recursos? Em que tipo de escolas eles poderiam ser alocados? Essas perguntas permeiam a obra e guiam os autores na construção de respostas, que culminam em um projeto de educação nacional com vistas ao desenvolvimento do País.

A fim de possibilitar essa reflexão, a saber, a presença da temática do financiamento da Educação no manifesto dos pioneiros, este artigo foi dividido em três partes. Na primeira, apresenta-se o contexto histórico do Brasil na década de 1930, na perspectiva de que o manifesto representa tentativas dos autores (atores ativos dos processos de construção da educação no período) de dar conta da realidade que os cercava, apresentando a ela respostas satisfatórias de acordo com suas expectativas para o País. A segunda parte traz a análise do documento e de como, nele, o tema do financiamento se configura. Por fim, na terceira parte, avaliam-se como as proposições do manifesto influenciaram a elaboração das políticas públicas de financiamento contemporâneas da virada do século XX para o XXI.

O Manifesto dos Pioneiros da Educação Nova é um documento que repercute até hoje no pensamento educacional brasileiro pela sua profundidade e abrangência. Ainda que se refira ao Brasil da primeira metade do século passado, é extremamente atual em suas 
avaliações e críticas, servindo de referência para os estudiosos da educação e de suas questões.

\section{O Brasil da década de 30: contradições e contrastes}

A década de 1930 foi marcada por um processo de transformações estruturais no País, concentrando em si as ebulições políticas, sociais, econômicas e culturais que já vinham sendo gestadas desde o final do século XIX e que ainda conviviam com elementos herdados do Império. A década anterior já anunciava as tensões provocadas por essas transformações na sua repercussão entre os diversos setores da sociedade, uma vez que o novo disputava espaço com o tradicional. Tais tensões podem ser vislumbradas nas novas configurações econômicas advindas com a industrialização; no surgimento de novos atores políticos e sociais, sobretudo nos movimentos tenentistas e na formação do Partido Comunista Brasileiro, PCB; na realização da Semana de Arte Moderna, dentre outros.

Na economia, a Primeira Grande Guerra (1914/18) permitiu a expansão, ainda que tímida, das indústrias, principalmente paulistas, o que levou a uma reformulação dos setores produtivos do campo e das cidades, assim como o estabelecimento de um novo padrão de acumulação de capital (CANO, 2007). Ainda segundo Cano (2007), a explosão da crise do liberalismo com a quebra da bolsa de Nova York em 1929 teve um duplo efeito, uma vez que, ao mesmo tempo em que impossibilitou a continuidade da política de valorização permanente do café - produto que era base da economia brasileira, em seu modal de exportação desde meados do século XIX -, suscitou uma contração das importações, estimulando as indústrias paulistas a diversificarem sua produção e a exportarem para o restante do País (CANO, 2007). Os estados não produtores de café, mas que se mantiveram agrário-exportadores ${ }^{1}$, sofreram mais com a crise, encontrando dificuldades para reorientarem seus investimentos ou avançarem na consolidação de sua indústria. É importante considerar que não havia necessariamente uma unidade dentro dos estados, entre os diversos setores da economia, coexistindo as elites agrárias com elementos progressistas que buscavam superar a focalização oficial nas camadas primário-exportadoras. Tais desequilíbrios regionais acabaram por acirrar uma competição intercapitalista durante toda a segunda metade da década de 1920, acirramento este que contribuiu para a eclosão do movimento de tomada de poder em 1930.

Com o objetivo de reequilibrar a correlação de forças, formou-se uma aliança que congregava em si elementos contraditórios, como representantes da velha política insatisfeitos com a predominância das oligarquias paulista, mineira e da capital federal, assim como representantes egressos dos movimentos tenentistas (PINHEIRO, 1991). Ainda que até pouco tempo tais grupos tenham sido adversários políticos, os interesses momentâneos permitiram que se aglutinassem em torno da Aliança Liberal. As elites mineiras, que estiveram atreladas aos acordos de sucessão de poder na Primeira República, também compuseram a Aliança Liberal, tendo em vista seu rompimento com a oligarquia paulista. Ainda que derrotados nas urnas, os aliancistas se articularam com forças armadas (fiéis aos extenentistas, que naquele momento, já ocupavam setores chave no Exército e Marinha), e após

\footnotetext{
Segundo Boris Fausto, a frente de oposição às elites paulistas compôs-se majoritariamente da classe dominante de uma região cada vez mais desvinculada dos interesses cafeeiros, Minas Gerais, e de áreas inteiramente desvinculadas, Rio Grande do Sul e Paraíba (FAUSTO, 1995, p. 102).
} 
o assassinato de João Pessoa, candidato a vice-presidente da chapa, tomaram o poder nas principais regiões do País. Segundo o historiador Francisco Iglésias, o sucesso do levante se deu de forma mais fácil do que se esperava (IGLÉSIAS, 1993), e, em poucos dias, o governo eleito já havia renunciado.

Para Iglésias (1993, p. 233), "[...] se aparentemente é simples mudança de poder, na verdade é muito mais, pois vai ter início uma revisão da vida nacional". Como era composto por grupos muito diferentes, não tardou para que as clivagens políticas dividissem o movimento. Apesar dos interesses contraditórios, a figura forte de Getúlio Vargas, chefe do governo provisório, foi central para a garantia da manutenção do grupo recém-empossado. Um dos primeiros atos de Vargas foi a criação do Ministério da Educação e Saúde, sob a responsabilidade do mineiro Francisco Campos, que reformou os ensinos primário e secundário.

No campo educacional, as mudanças na política e na economia nacional na década de 1920 foram acompanhadas por diversas reformas das redes de ensino de grandes municípios e de estados, como a de Sampaio Dória em São Paulo (1920), Lourenço Filho no Ceará (19221923), Anísio Teixeira na Bahia (1924), José Augusto Bezerra de Menezes no Rio Grande do Norte (1925-1928), Lisímaco Costa no Paraná (1927-1928), Francisco Campos em Minas Gerais (1928) e Fernando de Azevedo no Rio de Janeiro (1927-1930) (SAVIANI, 2007). Essas reformas tinham, de maneira geral, ancoragem teórica nas ideias do pedagogo suíço Johann Heinrich Pestalozzi e seu método indutivo ("lição de coisas") e, principalmente, na Escola Nova, através da vertente do filósofo e pedagogo norte-americano John Dewey, trazido para o Brasil por Rui Barbosa e Anísio Teixeira (que após uma temporada na Universidade de Colúmbia, quando obtém o título de mestre, trava contato com Dewey, traduzindo parte de suas obras no retorno ao Brasil).

É nesse contexto que é fundada em 1924, por iniciativa de Heitor Lyra, a Associação Brasileira de Educação, ABE, composta por grupos variados, em que disputavam hegemonia, principalmente os representantes da Escola Nova e setores da Igreja Católica ligados à Educação. A partir de 1927, a ABE organizou as Conferências Nacionais de Educação com o objetivo de discutir o cenário da educação brasileira e seu rumo em meio às mudanças que o país atravessava (SAVIANI, 2007). Na IV Conferência Nacional de Educação, já sob o Governo Provisório capitaneado por Vargas, é definida uma resolução de elaboração de um documento em que a $\mathrm{ABE}$ se posicionaria em relação ao que considerava ser vital para as reformas que já estavam em curso. Fernando de Azevedo ficou encarregado de ser o redator do texto, apesar de o documento vir assinado por 25 pessoas. Os membros da ABE ligados às escolas católicas, por discordarem frontalmente do teor do documento (e dos rumos que a entidade estava tomando), deixaram a $A B E$ e fundaram no ano seguinte a Confederação Católica Brasileira de Educação, CCBE.

O documento solicitado pela IV Conferência Nacional de Educação, intitulado Manifesto dos Pioneiros da Educação Nova, é publicado em jornais e folhetins e suscita uma importante discussão em toda a sociedade brasileira, influenciando inclusive na elaboração da Carta Constitucional de 1934, a segunda da República.

A Constituição de 1934 foi inovadora em relação a de 1891, abrangendo temas como família, educação, funcionalismo, segurança nacional e justiça eleitoral (IGLÉSIAS, 1993). Se, por um lado, o texto constitucional assegurava o federalismo, por outro, na prática, o governo 
Vargas centralizava cada vez mais o poder. No que concerne à legislação trabalhista, a Constituição era bastante avançada, o que incorrerá em novas relações entre patrões e empregados em um cenário cada vez mais urbano e proletarizado. Além disso, essa legislação, conjuntamente com a Consolidação das Leis Trabalhistas, CLT, servirão como moeda de troca de Vargas no trato com as classes trabalhadoras, quando da necessidade de apoio político. No tocante à educação, a Constituição de 1934 pela primeira vez estabelece que a Educação é direito de todos (art. ${ }^{\circ} 149$ ) e se manifesta sobre o financiamento (arts. ${ }^{\circ} 156$ e 157), disposições influenciadas diretamente pelo Manifesto de 1932.

O Manifesto influenciou também o novo ministro da educação, Gustavo Capanema, que exerceu o cargo de 1934 até o final do período Vargas, em 1945. O ministro se cercou de personalidades ligadas à cultura e ao movimento modernista de 1922, como os poetas Carlos Drummond de Andrade, Mario de Andrade e Manuel Bandeira, Rodrigo Melo Franco de Andrade, o músico Heitor Villa-Lobos, além dos escola-novistas Anísio Teixeira, Lourenço Filho e Fernando de Azevedo (CPDOC, 1997). As iniciativas do ex-ministro Francisco Campos foram aprofundadas e ampliadas no ministério de Capanema, sendo as mais destacadas a reforma do ensino secundário e a criação da Universidade do Brasil.

Entretanto, a Constituição de 1934 durou pouco tempo, sendo invalidada pelo chamado Golpe do Estado Novo. Segundo a carta magna, as eleições deveriam ser convocadas para o início de 1938. Porém, havia instabilidade política desde o levante comunista nos meios militares em 1935, habilmente utilizada por Vargas e por setores ligados ao Integralismo ${ }^{2}$ para criar um clima de medo entre empresários e a classe média. A campanha sucessória foi marcada pela questão da necessidade de defesa frente aos avanços comunistas e por uma bem articulada e construída unidade do exército sob a mão forte do presidente. A poucos meses das eleições, o Ministério da Guerra anunciou o descobrimento de um plano de tomada de poder de grupos ligados a Moscou ${ }^{3}$, foi o que bastava para a suspensão dos direitos constitucionais e o estabelecimento de um 'estado de guerra'. Com as unidades federativas sob intervenção, Vargas anunciou o cancelamento das eleições e a elaboração de uma nova constituição, outorgada por ele em 10 de novembro de 1937.

A Constituição do Estado Novo recuou em praticamente todos os pontos relativos à Educação que haviam sido conquistados na carta de 1934, como na questão da obrigatoriedade e garantia do acesso. Também concedeu benefícios e favorecimentos para as escolas particulares em detrimento das escolas públicas, uma vez que desobrigava os cofres governamentais de garantir a educação, ficando esta a cargo das famílias (art. $\left.{ }^{\circ} 130\right)$. 0 compromisso assumido pelo Estado era o ensino profissionalizante para as classes mais baixas (art. $\left.{ }^{\circ} 129\right)$.

O regime do Estado Novo perdurou de 1937 até 1945 e se caracterizou por um ideário de Estado forte, centralizador e nacionalista. Pautando-se por uma modernização do aparelho administrativo, conjugado com uma legislação social, não deixou de ser contraditório ao ser extremamente antidemocrático e perseguir opositores com violência (IGLÉSIAS, 1993). A

2 Corrente política que se derivou do tenentismo e que aderiu a um ideário inspirado no Fascismo Italiano. Tinha como principal líder o paulista Plínio Salgado.

3 Sobre o denominado Plano Cohen existem muitos versões e dúvidas sobre a veracidade do documento, porém, é consenso entre historiadores e cientistas políticos que o texto foi forjado por grupos que eram favoráveis a um governo mais centralizado e que exigiam ações mais enérgicas contra o comunismo (SILVA, 1980). 
grande intervenção na economia na forma de investimentos e incentivo à industrialização, agora não mais de pequenos bens de consumo, mas de bens de produção, intensificou a urbanização e a formação de uma classe trabalhadora urbana. Vargas objetivava modernizar o país, tirando-o do atraso no qual se encontrava em relação às potências europeias, espelhando-se nas rápidas conquistas econômicas dos governos fascistas da Europa Central. Apesar da expansão da rede rodoviária (rodovias Rio-Petrópolis; São Paulo-Santos; e São Paulo-Campinas), o crescimento econômico encontrou, como principal barreira, a precária infraestrutura do País (CANO, 2007).

Ainda que tenha sido derrubado por contradições internas que não suportaram as mudanças socioeconômicas e as novas relações de poder no final da Segunda Guerra Mundial (1939/45), o governo Vargas terminou a década de 1930 hegemônico, politicamente, com uma sólida atuação junto à população e a criação de um sentimento de nacionalidade até então desconhecido no País.

A década, que havia se iniciado com amplas reformas dos sistemas de ensino nos estados e no distrito federal, em que a Educação havia sido alçada à condição de problema mais grave dentre os problemas nacionais, segundo o Manifesto dos Pioneiros, sendo inclusive objeto de importantes pontos da Constituição de 1934, termina com a Educação relegada a segundo plano por um governo ditatorial.

\section{A Questão do Financiamento no Documento/Monumento Manifesto dos Pioneiros}

O Manifesto dos Pioneiros da Educação Nova, produzido por ocasião da IV Conferência Nacional de Educação, foi fundamental para a consolidação de uma corrente que já vinha se expandindo pelo País, não só nas concepções pedagógicas (Método Indutivo e as contribuições dos avanços da Psicologia Cognitiva para a Educação), como também nas propostas de mudanças políticas e sociais. Sendo assim, as discussões que conduziram ao texto final favoreceram a formação de certa unidade da ABE em torno das propostas, fazendo deste grupo, até então corrente interna da associação, um verdadeiro movimento de renovação com alcance em todo o Brasil. O Manifesto pode ser considerado como uma das pedras fundamentais do pensamento pedagógico brasileiro, sendo abordado em nossa análise como um documento/monumento.

Segundo o historiador francês Jacques Le Goff, a memória coletiva e a História (forma científica dessa memória) se manifestam como monumentos ou como documentos. Como memórias do passado, "[...] os monumentos têm como características o ligar-se ao poder de perpetuação, voluntária, das sociedades históricas (é um legado à memória coletiva) e o reenviar a testemunhos que só numa parcela mínima são escritos" (LE GOFF, 1990, p. 536). Ou seja, sua fabricação pressupõe intencionalidade. Já o documento, palavra derivada do latim docere, ensinar, se firma como prova na Idade Média, como algo a ser apreendido, um vestígio do passado. A historiografia positivista no século XIX irá garantir o triunfo do documento sobre o monumento como principal instrumento para o estudo da memória e da História. O documento, segundo essa concepção, era neutro, enquanto o monumento era a materialização manipulada do passado. O século $X X$ traz consigo uma revolução no campo do conhecimento histórico, com uma nova forma de se analisar o passado e/os documentos (a chamada Escola dos Annales). Essa revolução é ao mesmo tempo quantitativa e qualitativa 
(LE GOFF, 1990), e os documentos passam a ser lidos de forma mais crítica, não como provas fidedignas do passado, mas eles mesmos, em suas condições de produção, como objetos de reflexão. Com essa revolução documental, a ilusão positivista de um documento isento de parcialidades é posta abaixo. O documento é ele mesmo um monumento e como tal deve ser lido.

O documento não é qualquer coisa que fica por conta do passado, é um produto da sociedade que o fabricou segundo as relações de forças que aí detinham o poder. Só a análise do documento enquanto monumento permite à memória coletiva recuperálo e ao historiador, usá-lo cientificamente, isto é, com pleno conhecimento de causa (LE GOFF, 1990, p. 545, grifo nosso).

Nesse sentido, o Manifesto dos Pioneiros foi escrito dirigido ao povo e ao governo, assumindo desde já sua intenção de dialogar com o conjunto da sociedade brasileira. Em sua primeira frase, já se posiciona em relação às prioridades que vai estabelecer ao longo do texto, se contrapondo à tendência das discussões políticas da década de 1930 (como exposto acima), que colocavam a questão econômica como central para o desenvolvimento do País:

\begin{abstract}
Na hierarquia dos problemas nacionais, nenhum sobreleva em importância e gravidade ao da educação. Nem mesmo os de caráter econômico lhe podem disputar a primazia nos planos de reconstrução nacional. Pois, se a evolução orgânica do sistema cultural de um país depende de suas condições econômicas, é impossível desenvolver as forças econômicas ou de produção, sem o preparo intensivo das forças culturais e o desenvolvimento das aptidões à invenção e à iniciativa que são os fatores fundamentais do acréscimo de riqueza de uma sociedade (MANIFESTO de 1932, 2006, p. 188).
\end{abstract}

A contextualização histórica dos 43 anos de república até aquele momento (1889-1932), com especial atenção para as variadas reformas que se sobrepunham umas às outras, sem nenhuma organização, serve de base para a afirmativa conclusiva de que "[...] a principal causa desse estado [...] é na falta, em quase todos os planos e iniciativas, da determinação dos fins da educação (aspecto filosófico e social) e da aplicação (aspecto técnico) dos métodos científicos aos problemas da educação" (MANIFESTO de 1932, 2006, p. 188).

Por aspecto filosófico e social, o manifesto irá problematizar a finalidade da educação e sua função para com a formação humana e profissional da população, assim como a natureza pedagógica dessa educação. $\mathrm{O}$ aspecto técnico diz respeito à administração da educação e seu financiamento. Tanto no aspecto filosófico e social, como no técnico, o Manifesto aponta a falta de uma visão global nas diversas reformas implementadas até então, sendo urgente não mais reformas, mas uma reforma, embasada em um plano integral que não corresse o risco de se fragmentar com as mudanças políticas e econômicas que eventualmente ocorressem (MANIFESTO de 1932, 2006, p. 190).

De acordo com os autores que assinaram o Manifesto, tal plano integral comportaria como finalidade da educação uma reação categórica, intencional e sistemática contra a velha estrutura da educação, sustentada pelo privilégio, artificial e distanciada das questões práticas da vida cotidiana. A educação nova, para os autores, teria uma feição mais humana, buscando formar cidadãos capacitados biológica e socialmente, para viverem em uma sociedade democrática. Ou seja, deveria haver um deslocamento do enfrentamento dos problemas da educação do aspecto da administração para o plano político-social (MARTINS; PINTO, 2014). 
Do ponto de vista do aspecto técnico, a educação deveria ter, como pontos elementares, ser pública, como função essencial e primordial do Estado (sobrepondo-se inclusive à família, mesmo que não prescindindo dela); única, no sentido de comum a todos, opondo-se aos privilégios alicerçados no sistema antigo, em que alguns eram educados para os ofícios intelectuais e de mando enquanto outros eram educados para os trabalhos manuais e subservientes; laica, gratuita e obrigatória, para que as crianças não ficassem à mercê de grupos, classes ou crenças, mas recebessem uma educação igualitária (MANIFESTO de 1932, 2006, p. 192-193).

Todavia, nenhum desses elementos poderia ser constituído sem que existisse uma autonomia da Educação. Em outras palavras, é impossível qualquer perspectiva de renovação, seja filosófico-social ou técnica da educação, sem que se criassem meios para que ela não estivesse sujeita às transitoriedades e vicissitudes de governos, partidos políticos ou caprichos pessoais do momento. Segundo o entendimento dos autores do Manifesto, a educação deveria ser tratada com uma política integral e permanente de Estado e não apenas como programas de governo (MANIFESTO de 1932, 2006, p. 194).

Sendo assim, a questão do financiamento pode ser considerada um dos elementos centrais em toda a construção explicitada no Manifesto. A linha de raciocínio traçada pelos autores chega à pessimista constatação de que

\begin{abstract}
Toda a impotência manifesta do sistema escolar atual e a insuficiência das soluções dadas às questões de caráter educativo não provam senão o desastre irreparável que resulta, para a educação pública, de influências e intervenções estranhas que conseguiram sujeitá-la a seus ideais secundários e interesses subalternos. Daí decorre a necessidade de uma ampla autonomia técnica, administrativa e econômica, com que os técnicos e educadores, que têm responsabilidade e devem ter, por isto, a direção e administração da função educacional, tenham assegurados os meios materiais para poderem realizá-la. Esses meios, porém, não podem reduzir-se às verbas que, nos orçamentos, são consignadas a esse serviço público e, por isso, sujeitas às crises dos erários do Estado ou às 'oscilações' do interesse dos governos pela educação. A autonomia econômica não poderá se realizar, a não ser pela instituição de um 'fundo especial ou escolar', que constituído de patrimônios, impostos e rendas próprias, seja administrado e aplicado exclusivamente no desenvolvimento da obra educacional, pelos próprios órgãos do ensino, incumbidos de sua direção (MANIFESTO de 1932, 2006, p. 194-195, grifos nossos).
\end{abstract}

Naquele momento, os recursos repassados para a educação eram destinados mediante a rubricas que o governo assinava, porém, nada garantia que haveria continuidade de tais recursos. A proposta do Manifesto era a constituição de um fundo escolar, composto de patrimônios, impostos e rendas próprias, que tivesse destinação exclusiva para a educação. Assim, esse fundo não estaria sujeito às flutuações orçamentárias e nem estaria dependente da boa vontade dos gestores públicos. Essa destinação também seria para a construção de Universidades, nas quais se formariam os professores do ensino primário e secundário.

Tanto a arrecadação quanto a aplicação dos recursos deveriam seguir a lógica de descentralização da educação que perpassa todo o Manifesto. A União coordenaria o processo, mas este seria implementado e assegurado pelas escolas, localidades e municípios. Assim, haveria uma tendência à diminuição dos desvios de recursos e investimentos nos problemas por aqueles que os conheciam de perto. 
A questão do financiamento da educação também está relacionada com os confrontamentos dos pioneiros com setores ligados às escolas católicas, tanto no âmbito do financiamento destas escolas com recursos públicos, como pela própria existência do ensino religioso nas escolas oficiais. Os autores do Manifesto questionavam o fato de que considerável parte dos já escassos recursos da educação estava sendo enviada para escolas particulares, assim como criticavam a manutenção dos pontos das reformas de Francisco Campos que garantiam o ensino religioso nas escolas públicas. Os embates entre católicos e pioneiros no Manifesto se dão dentro das concepções de educação e da natureza do homem, sendo que, enquanto aqueles defendiam uma educação voltada para a formação do "homem ideal", estes entendiam a educação como veículo integrador das novas gerações às condições de um mundo sempre mutante ${ }^{4}$. As disputas entre os dois grupos se intensificarão no final da década de 1950, com as questões das escolas públicas versus escolas particulares (majoritariamente escolas confessionais católicas), que culminarão com a publicação de um novo manifesto, basicamente composto pelo mesmo grupo que assinou o documento de 1932, denominado Manifesto dos Educadores: mais uma vez convocados.

O financiamento público da educação aparecerá como um dos elementos fundamentais na consolidação de um projeto integral de ensino apregoado pelo Manifesto dos Pioneiros. Seria esse financiamento que garantiria a existência das demais políticas necessárias para a renovação do ensino? Sem uma perspectiva permanente de captação e distribuição de recursos, nenhuma proposta de mudança real subsistiria. Os elementos presentes no manifesto incidiram nas elaborações da Carta Constitucional de 1934, como, por exemplo, no estabelecimento de uma vinculação da receita de impostos para a educação (União e Municípios, 10\%, e Estados e Distrito Federal, 20\%), assim como na reserva de parte dos patrimônios territoriais para a formação de fundos escolares (MARTINS; PINTO, 2014).

Além disso, esses recursos previstos na Constituição somente poderiam ser aplicados no que se chamou de manutenção e desenvolvimento dos sistemas educativos. Entretanto, as conquistas suscitadas pelo Manifesto dos Pioneiros foram rapidamente desconstruídas com o golpe do Estado Novo. O texto que tão bem avaliava a realidade conjuntural brasileira se transformou em apenas uma lembrança de um período em que se apresentavam projetos de país, no qual venceu o modelo ditatorial varguista, repressor das vozes dissonantes, e que desconstruiu o sistema de educação pública, favorecendo os interesses dos grupos dominantes.

\section{A herança do Manifesto dos Pioneiros}

Passados mais de 80 anos de sua publicação, o Manifesto dos Pioneiros ainda influencia as discussões sobre educação no Brasil. Suas contribuições ao debate educacional brasileiro permanecem atuais, dada a permanência de muitos dos problemas levantados pelos redatores do documento. No tocante ao financiamento, as principais formulações legais dos anos de 1990 a 2000 são de alguma forma inspiradas na proposta de organização de financiamento dos autores do texto de 1932 (ARELARO, 2014), guardadas as devidas diferenças conjunturais do contexto de formulação do Manifesto, com uma ação reduzida do

4 Para mais informações sobre as concepções de educação opostas de pioneiros e católicos, ver a Ideologia e Educação Brasileira: Católicos e liberais, baseado na dissertação de mestrado defendida por Carlos Roberto Jamil Cury em São Paulo, 1977. 
Estado para com as políticas sociais, um mercado voltado para os interesses agrárioexportadores, e com um arranjo federativo menos complexo (CASTRO, 2014).

O atual modelo de financiamento da educação básica no Brasil tem como base as discussões sociais e políticas que marcaram o País durante o processo de reabertura, no final da década de 1970. Essas discussões, de alguma maneira, retomam aspectos previstos no Manifesto dos Pioneiros (MARTINS; PINTO, 2014) e que já haviam sido colocados na Carta Constitucional de 1934 e subtraídos na Constituição do Estado Novo de 1937. A Constituição Federal de 1988 (CF/88), em seu artigo 212, garantiu o financiamento público da educação ao afirmar que

A União aplicará, anualmente, nunca menos de dezoito, e os Estados, o Distrito Federal e os Municípios vinte e cinco por cento, no mínimo, da receita resultante de impostos, compreendida a proveniente de transferências, na manutenção e desenvolvimento do ensino (BRASIL, 1988, p. 1).

Sendo assim, a vinculação de recursos provenientes da arrecadação de impostos para a educação passa a ser preceito legal garantido, e sua aplicação, objeto de análise e fiscalização por parte da sociedade brasileira organizada.

Outra proximidade, entre os preceitos propostos pelo Manifesto e a forma de organização do sistema contemporâneo de financiamento, é a organização de fundos de financiamento escolares, a fim de garantir recursos mínimos exclusivos para a educação. $O$ Fundo de Manutenção e Desenvolvimento do Ensino Fundamental e de Valorização dos Profissionais da Educação (FUNDEF) é criado a partir da Lei 9.424 de 24 de dezembro de 1996 e passa a ser a referência jurídica para o financiamento público da educação brasileira. Sua existência estava prevista pelo prazo de 10 anos. Sua regulamentação se dá com o Decreto $N^{\circ} 2.264$, de 27 de junho de 1997.

Segundo essa lei, o fundo seria constituído pela vinculação de porcentagens dos impostos e transferências constitucionais entre entes federados, como as que compõem o Fundo de Participação dos Estados e dos Municípios. Tais porcentagens seriam depositadas em uma conta criada especificamente para esse fim, sob responsabilidade dos Estados e dos Municípios, e conforme o art. 6 da Lei 9.424/96, a União complementaria o fundo caso a arrecadação não atingisse o mínimo previsto, tendo como base o número de matrículas:

Art. $6^{\circ} \mathrm{A}$ União complementará os recursos do Fundo a que se refere o art. $1^{\circ}$ sempre que, no âmbito de cada Estado e do Distrito Federal, seu valor por aluno não alcançar o mínimo definido nacionalmente.

$\S 1^{\circ} \mathrm{O}$ valor mínimo anual por aluno, ressalvado o disposto no $\S 4^{\circ}$, será fixado por ato do Presidente da República e nunca será inferior à razão entre a previsão da receita total para o Fundo e a matrícula total do ensino fundamental no ano anterior, acrescida do total estimado de novas matrículas, observado o disposto no art. $2^{\circ}, \S 1^{\circ}$, incisos I e I.

$\S 2^{\circ}$ As estatísticas necessárias ao cálculo do valor anual mínimo por aluno, inclusive as estimativas de matrículas, terão como base o censo educacional realizado pelo Ministério da Educação e do Desporto, anualmente, e publicado no Diário Oficial da União.

$\S 3^{\circ}$ As transferências dos recursos complementares a que se refere este artigo serão realizadas mensal e diretamente às contas específicas a que se refere 0 art. $3^{\circ}$. [...] (BRASIL, 1996, p. 28442). 
Mais uma herança do Manifesto pode ser percebida na limitação da destinação de recursos. Todas as verbas provenientes do FUNDEF somente podem ser gastas com a chamada Manutenção e Desenvolvimento do Ensino (MDE), não podendo ser destinadas a nenhuma outra utilização. Por manutenção e desenvolvimento do ensino, entendem-se ações que busquem estabelecer e alcançar objetivos básicos da educação previstos na legislação, seja na forma de aquisição de insumos indispensáveis para a promoção da educação e na remuneração dos profissionais da educação básica, ou seja, todas as ações que visem à obtenção dos objetivos das instituições educacionais em todos os níveis.

Quando os dez anos de vigência do FUNDEF se esgotaram, foi lançada a Lei 11.494, que instituiu o Fundo de Manutenção e Desenvolvimento do Ensino Básico e de Valorização dos Profissionais da Educação, o FUNDEB. Basicamente, as diferenças entre o FUNDEF e o FUNDEB se encontram no campo de abrangência dos fundos. Enquanto o FUNDEF era específico para o Ensino Fundamental, o FUNDEB contempla a educação infantil, anos iniciais e finais do Ensino Fundamental urbano e rural, Ensino Médio urbano e rural, Ensino Médio profissionalizante, Educação de Jovens e Adultos e Educação Especial, além da Educação Indígena e de Quilombolas. Os percentuais vinculados que formam o FUNDEB também são maiores do que aqueles que formavam o FUNDEF.

\section{Considerações Finais}

O Manifesto surgiu em um contexto de disputas e combates não só pelos rumos que a educação deveria tomar, mas também pelos projetos de país que estavam em questão. Aliás, o Manifesto representava um desses projetos, que guardava proximidades com o pensamento liberal que se consolidava no País e que propunha a modernização e industrialização do Brasil. Apesar de suas contradições e limites, o Manifesto pode ser considerado um projeto progressista, que procurava alçar a educação como o principal dos problemas nacionais e, sem a qual, os demais não poderiam ser supridos.

A questão do financiamento pode ser entendida como uma das componentes do núcleo principal das mudanças reivindicadas pelos pioneiros, uma vez que, sem um sistema nacional, descentralizado, com autonomia econômica e com recursos garantidos, dificilmente qualquer uma das outras proposições poderia ser levada a cabo. Um fundo composto por recursos próprios de impostos e de patrimônios permitiria a elaboração de políticas permanentes para a educação, a expansão das redes de ensino, assim como a criação de Universidades para a formação dos professores do primário e secundário.

Apesar de não ter sido o projeto vencedor no período de sua elaboração, o Manifesto dos Pioneiros da Educação Nova acabou se transformando em um marco do pensamento educacional e pedagógico do Brasil e que, conjuntamente com o Manifesto dos Educadores de 1959, constitui-se como um dos documentos/monumentos fundamentais para se compreender a história da Educação no Brasil e que até hoje repercute nas elaborações de políticas públicas para a Educação.

\section{Referências}

ARELARO, Lisete R. G. Carta de apresentação. In: CUNHA, Célio da et al. (Org.). O Sistema Nacional de Educação: diversos olhares 80 anos após o Manifesto. Brasília: MEC/SASE, 2014. p. 4-6. 
BRASIL. Constituição da República dos Estados Unidos do Brasil (de 16 de julho de 1934). Diário Oficial, Rio de Janeiro, 16 jul. 1934. Disponível em: <http://www.planalto.gov.br/ ccivil_03/constituicao/constituicao34.htm>. Acesso em: 01 mar. 2018.

BRASIL. Constituição dos Estados Unidos do Brasil (de 10 de novembro de 1937). Diário Oficial, Rio de Janeiro, 10 nov. 1937. Disponível em: <http://www.planalto.gov.br/ccivil_03/ constituicao/constituicao37.htm>. Acesso em: 01 mar. 2018.

BRASIL. Constituição da República Federativa do Brasil: promulgada em 05 de outubro de 1988. Diário Oficial da União, Brasília, 1988.

BRASIL. Lei 9.424, de 24 de dezembro de 1996. Dispõe sobre o Fundo de Manutenção e Desenvolvimento do Ensino Fundamental e de Valorização do Magistério, na forma prevista no art. $60, \S 7^{\circ}$, do Ato das Disposições Constitucionais Transitórias, e dá outras providências. Diário Oficial da União, Brasília, 26 dez. 1996.

BRASIL. Lei 11.494, de 20 de junho de 2007. Regulamenta o Fundo de Manutenção e Desenvolvimento da Educação Básica e de Valorização dos Profissionais da Educação FUNDEB. Diário Oficial da União, Brasília, 20 jun. 2007.

CANO, Wilson. Desequilíbrios Regionais e Concentração Industrial no Brasil 1930-1970. 3. ed. São Paulo: Editora UNESP, 2007.

CASTRO, Jorge Abrahão de. Dilemas para o financiamento da educação. In: CUNHA, Célio da et al. (Org.). O Sistema Nacional de Educação: diversos olhares 80 anos após o Manifesto. Brasília: MEC/SASE, 2014. p. 178-196.

CPDOC. A Era Vargas - $1^{\circ}$ tempo - dos anos 20 a 1945 Dossiê A Era Vargas. In: FGV. CPDOC. Navegando na História. Rio de Janeiro; São Paulo, 1997. Disponível em: $<$ https://cpdoc.fgv.br/producao/dossies/AEraVargas1/apresentacao>. Acesso em: 01 mar. 2018.

CURY, Carlos Roberto Jamil. Ideologia e Educação Brasileira: católicos e liberais. 2. ed. São Paulo: Cortez/Autores Associados, 1984. (Coleção Educação Contemporânea).

IGLÉSIAS, Francisco. Trajetória política do Brasil: 1500-1964. São Paulo: Companhia das Letras, 1993.

LE GOFF, Jacques. Documento/Monumento. In: LE GOFF, Jacques. História e Memória. Tradução Bernardo Leitão et al. Campinas: Editora da Unicamp, 1990.

FAUSTO, Boris. A Revolução de 1930. Historiografia e História. São Paulo: Companhia das Letras, 1995.

MANIFESTO dos Pioneiros da Educação Nova (1932). Revista HISTEDBR On-line, Campinas, n. especial, p. 188-204, ago. 2006. Disponível em: <http://www.histedbr.fe. unicamp.br/revista/edicoes/22e/doc1_22e.pdf>. Acesso em: 01 mar. 2018.

MARTINS, Paulo de S.; PINTO, José Marcelino de R. Como seria o financiamento de um sistema nacional de educação na perspectiva do Manifesto dos Pioneiros da Educação Nova. In: CUNHA, Célio da et al. (Org.). O Sistema Nacional de Educação: diversos olhares 80 anos após o Manifesto. Brasília: MEC/SASE, 2014. p. 152-179. 
Combates pela Educação

PINHEIRO, Paulo Sérgio. Estratégias da llusão. A revolução mundial e o Brasil 1922-1935. 2. ed. São Paulo: Companhia das Letras, 1991.

SAVIANI, Demerval. História das ideias pedagógicas no Brasil. Campinas: Autores Associados, 2007.

SILVA, Hélio. A ameaça vermelha: o plano Cohen. Porto Alegre: L\&PM, 1980.

Daniel Santos Braga é doutorando em Educação: Conhecimento e Inclusão Social pela Universidade Federal de Minas Gerais, com pesquisa no campo de Políticas Públicas em Educação. Mestre em Educação e Formação Humana pela Universidade do Estado de Minas Gerais, com pesquisa na área do Financiamento Público da Educação e a Valorização do Magistério. Possui experiência docente e como coordenador pedagógico na educação básica na Rede Estadual de Minas Gerais e na Prefeitura de Belo Horizonte. Áreas de interesse: Valorização de Professores; Políticas Públicas em Educação; Financiamento da Educação; Associativismo e Sindicalismo Docente; História. Administração e gestão pública.

E-mail: danielsantosbraga@gmail.com 


\title{
Editores do volume 8
}

José Marcelino de Rezende Pinto - Universidade de São Paulo, São Paulo/SP, Brasil

Nalú Farenzena - Universidade Federal do Rio Grande do Sul, Porto Alegre/RS, Brasil

\section{Comitê Editorial}

José Marcelino de Rezende Pinto - Universidade de São Paulo, Brasil

Juca Gil - Universidade Federal do Rio Grande do Sul, Brasil

Theresa Adrião - Universidade Estadual de Campinas, Brasil Ângelo

Ricardo de Souza - Universidade Federal do Paraná, Brasil

Márcia Aparecida Jacomini - Universidade Federal de São Paulo, Brasil

\section{Conselho Editorial}

\section{Alejandro Morduchowicz}

Universidad Pedagógica, Provincia de Buenos Aires, Argentina

Fernanda Saforcada

Universidade de Buenos Aires, Argentina

Jacques Velloso

Universidade de Brasília, Brasil

João Monlevade

Senado Federal, Brasil

Jorge Abrahão de Castro

Instituto de Pesquisa Econômica Aplicada / IPEA, Brasil

Juca Gil

Universidade Federal do Rio Grande do Sul, Brasil

Lisete Regina Gomes Arelaro

Universidade de São Paulo, Brasil

Luis Carlos Sales

Universidade Federal do Piauí, Brasil

Luiz de Sousa Junior

Universidade Federal da Paraíba, Brasil

Luiz Fernandes Dourado

Universidade Federal de Goiás, Brasil

Magna França

Universidade Federal do Rio Grande do Norte, Brasil

\section{Maria Beatriz Luce}

Universidade Federal do Pampa, Brasil

Universidade Federal do Rio Grande do Sul, Brasil

Marcos Edgar Bassi

Universidade Federal do Paraná, Brasil

\author{
Maria Dilnéia Espíndola Fernandes \\ Universidade Federal de Mato Grosso do Sul, Brasil \\ Nalú Farenzena \\ Universidade Federal do Rio Grande do Sul, Brasil \\ Nelson Cardoso do Amaral \\ Universidade Federal de Goiás, Brasil \\ Nicholas Davies \\ Universidade Federal Fluminense, Brasil \\ Rosana Evangelista Cruz \\ Universidade Federal do Piauí, Brasil \\ Rosana Gemaque \\ Universidade Federal do Pará, Brasil \\ Robert E. Verhine \\ Universidade Federal da Bahia, Brasil \\ Romualdo Portela de Oliveira \\ Universidade de São Paulo, Brasil \\ Theresa Adrião \\ Universidade Estadual de Campinas, Brasil \\ Tristan McCowan \\ University of London, Reino Unido \\ Vera Jacob \\ Universidade Federal do Pará, Brasil \\ Vera Peroni \\ Universidade Federal do Rio Grande do Sul, Brasil \\ Vitor Henrique Paro \\ Universidade de São Paulo, Brasil
}

\section{Equipe editorial}

Apoio ao Comitê Editorial: Patrícia Balthazar Garcia

Diagramação, Revisão de português e normalização: Edson Leonel de Oliveira

Revisão de inglês: Ananyr Porto Fajardo 